\title{
SOB O CREDO VERMELHO: ÍNDIOS, COMUNISTAS E REVOLTA NO SUL DE MATO GROSSO EM MEADOS DO SÉCULO XX
}

Under the red creed: indians, communists and revolt in southern Mato Grosso in mid-twentieth century Bajo el credo rojo: indios, comunistas y revuelta en el sur de Mato Grosso a mediados del siglo XX

JOSÉ MANUEL FLORES 


\title{
Resumo
}

Com base no uso do Fundo Documental do Serviço de Proteção aos Índios (SPI), o artigo se propõe mostrar como duas tentativas de revolta dirigidas contra o domínio exercido pelo SPI sobre âmbitos importantes da vida indígena constituíram um movimento construído junto à ampla mobilização popular conduzida pelo Partido Comunista do Brasil (PCB), num contexto dominado pela crise de agosto de 1954 e os processos eleitorais de 1955. A partir de noções sobre a antropologia da formação do Estado, mostra-se como esse movimento incrustou-se em relações estruturais prévias, de caráter clientelístico e instituídas pelo SPI, e como essas mesmas relações, que cotidianamente reproduziam o poder do Estado, foram também o lugar onde se construiu o conflito e a revolta.

Palavras-Chave: Kaiowá, comunistas, revolta, PCB, SPI.

\begin{abstract}
Based on the use of the Documentary Fond of the Indian Protection Service (SPI), this article intends to show how two attempts at revolt against the dominance exercised by the SPI on important areas of indigenous life constituted a movement built next to the wide popular mobilization directed by the Brazilian Communist Party $(P C B)$, in a context dominated by the crisis of 1954 and the electoral process of 1955. From notions of the anthropology of the formation of the State, it is shown how this movement was embedded in previous structural relations, of clientele character, instituted by the SPI, and how these same relations, which daily reproduced the power of the state, were the place where conflict and revolt were built.
\end{abstract}

KeYwords: Kaiowá, communists, revolts, PCB, SPI.

\section{RESUMEN}

Con base en el uso del Fondo Documental del Serviço de Proteção aos índios (SPI) ,este artigo se propone mostrar como dos intentos de revuelta contra el domino ejercido por el SPI sobre ámbitos importantes de la vida indígena constituyeron un movimiento construido junto a la amplia movilización popular dirigida por el Partido Comunista Brasileño (PCB), en un contexto dominado por la crisis de 1954 y el proceso electoral de 1955. A partir de nociones de la antropología de la formación del Estado, se muestra cómo ese movimiento se incrustó en relaciones estructurales previas, de carácter clientelar, instituidas por el SPI, y cómo esas mismas relaciones, que cotidianamente reproducían el poder del Estado, fueron el lugar en donde se construyó el conflicto y la revuelta.

Palabras Clave: Kaiowá, comunistas, revuelta, PCB, SPI. 


\section{INTRODUÇÃO}

$\mathrm{E}$ m 1956, os Kaiowá do sul do antigo estado de Mato Grosso, na fronteira com o Paraguai, chegaram a comprometer seriamente a administração local do Serviço de Proteção aos Índios (SPI) ao propor a deposição violenta dos encarregados dos Postos Indígenas (PI) Francisco Horta e José Bonifácio. Nos primeiros meses desse ano, os funcionários do SPI "descobriram" uma conspiração dos índios para atacar o primeiro posto, localizado nas proximidades da pequena cidade de Dourados. Meses depois, outro grupo tentaria, também sem sucesso, tomar o controle do segundo PI. As duas tentativas de revolta contra o domínio exercido pelo SPI sobre âmbitos importantes da vida indígena se inscreveram dentro da corrente de lutas populares liderada pelo Partido Comunista do Brasil (PCB) no turbulento contexto político que levou ao fim do segundo mandato de Getúlio Vargas (1951-1954).

A oposição conservadora ao projeto nacional-desenvolvimentista do governo, representada pela União Democrática Nacional (UDN), setores das Forças Armadas, segmentos do empresariado e órgãos da grande imprensa, culminaria em agosto de 1954 com a morte do presidente. 0 suicídio de Vargas, ante um golpe de Estado em curso, possibilitou a rearticulação de interesses em face das eleições presidenciais de outubro de 1955. Neste quadro, o PCB, agindo na ilegalidade desde 1947, passou a se aproximar dos movimentos getulistas, depois de manter um cerrado ataque a Vargas e durante todo o seu governo.

0 propósito deste artigo é descrever a participação indígena na conturbada vida política brasileira em meados do século passado. É através de uma etnografia histórica que pretendo mostrar que essas revoltas frustradas, expressões de um profundo descontentamento, não resultaram de uma explosão repentina, mas sim de um movimento organizado, construído dentro da ampla mobilização popular dirigida pelo PCB, num momento conjuntural da vida do país. Essa articulação funcionou para visibilizar as demandas indígenas no âmbito de lutas nacionais, embora discretamente, assim como para organizar seus próprios conflitos internos e reproduzir, em nível local, a convulsão política brasileira. Entre 1954 e 1956, não apenas as aldeias dividiram-se politicamente entre os Kaiowá, simpatizantes do PCB, e o grupo opositor, ligado ao SPI; também se organizaram, logo após os comícios nacionais acontecerem, eleições locais para dirimir o confronto. 0 resultado adverso para os indígenas comunistas determinaram o caminho da revolta. ${ }^{1}$ 
O engajamento dos Kaiowá na vida política nacional e sua tentativa de libertação do domínio do SPI não diziam respeito apenas ao desejo de acabar com a opressão que a instituição indigenista representava. Como os críticos do conceito de resistência insistiram, as sociedades não estão divididas em dois blocos homogêneos, claramente diferenciados e opostos (cf. Orter, 1995; Gledhill \& Shell, 2012): a luta dos Kaiowá comunistas na década de 1950 esteve engajada também em profundas disputas internas pelo controle dos PI. Não é suficiente apenas mostrar como os indígenas estavam articulados politicamente com um mundo mais vasto. É importante descrever os confrontos e contradições internas em que essa luta se encontrava engajada. Esses conflitos eram estruturais e inerentes à sociedade indígena, então sob o domínio do SPI, que instituiu uma estrutura clientelística através da qual o poder do Estado era reproduzido cotidianamente.

No entanto, nem tudo resultava apenas na reprodução das velhas estruturas. Diversos estudos têm contribuído para desmitificar a coerência estrutural que frequentemente se atribui ao Estado (Joseph \& Nugent, 1994; Corrigan \& Sayer, 1985; Lima, 2002). Neles, trata-se de conceber o Estado não como algo dado e sim como algo em constante atualização, ressaltando as dimensões processuais da sua dinâmica ou formação. Apesar de os Estados apresentarem "uma arquitetura sólida", Eric Wolf (2003) propõe que eles são mais bem pensados como areias multidimensionais nas quais diferentes grupos competem por recursos, utilizando todos os meios possíveis - tecnológicos, organizacionais, ideológicos - para ocupar nódulos estratégicos na distribuição do poder. Esses nódulos, acrescenta Wolf, sempre são contestados. Assim, foi dentro da mesma prática "clientelística" (aqui entendida como um campo de poder) que cotidianamente edificava o poder do Estado que os Kaiowá foram capazes de conceber um movimento político contra esse domínio exercido pelo SPI; quer dizer, as práticas que cotidianamente constituem e reproduzem o poder do Estado são também o lugar onde se constrói o conflito e a revolta.

0 presente artigo foi escrito a partir da documentação da 5a Inspetoria Regional do SPI (IR5), arquivada no Museu do Índio, no Rio de Janeiro, bem como de algumas fontes hemerográficas. Não se trata apenas de uma documentação de caráter administrativo; encontram-se também centenas de cartas e comunicações pessoais tanto de funcionários quanto de indígenas, que oferecem valiosos detalhes sobre o período em questão e que, em grande medida, ainda permanecem inexploradas. Apesar das múltiplas referências que podemos encontrar nessas fontes, a participação política indígena junto ao PCB tem sido pouco estudada, com alguma exceção (Lins, 2007). A ação política indígena no marco do Estado nacional geralmente tem sido pensada dentro das fronteiras do indigenismo e do exercício da tutela. Este texto pretende explorar esse outro aspecto da historia política Kaiowá. 


\section{CONSPIRAÇÃO E REVOLTA}

$\mathrm{O}$

s PI eram o espaço concreto da aplicação da política indigenista do SPI, baseada em noções particulares de tutela e evolução, visando à progressiva integração dos índios à nação:² possuíam jurisdição sobre uma ou várias aldeias e contavam com infraestrutura administrativa, escolar e produtiva, com frequência muito precárias, sob a condução direta de um encarregado residente no posto e subordinado a uma chefia regional, localizada em Campo Grande: a 5a Inspetoria Regional (IR5). Os conflitos entre indígenas e encarregados, basicamente de caráter clientelístico, eram cotidianos desde que os PI foram instalados na segunda década do século XX, mas entre 1954 e 1956 esses confrontos tomaram um caminho distinto que refletiria as tendências do cenário nacional.

As tentativas de revoltas em 1956 contra o SPI, representado pelos encarregados dos postos, embora constituíssem um só movimento, foram dois eventos separados no tempo e no espaço. 0 primeiro, reduzido a uma conspiração logo descoberta, ocorreu no começo daquele ano, no PI Francisco Horta, localizado nas imediações da cidade de Dourados. O segundo, meses depois, em outubro, foi uma aberta iniciativa indígena para tomar o controle do PI José Bonifácio, a 150 km do anterior e próximo de Caarapó.

A primeira tentativa foi, de certa forma, anunciada no semanário O Democrata, vinculado à vigorosa imprensa popular do PCB, e sediado em Campo Grande. Em fevereiro, o jornal publicou uma denúncia anônima contra o encarregado do PI, Alaor Fioravanti. O funcionário foi acusado de vender madeiras pertencentes à reserva, de falta de medicamentos no posto, de pagamentos irregulares aos diaristas indígenas e de ameaças de expulsão aos índios inconformados, tachando-os de comunistas. A resposta do chefe da IR5, Deocleciano de Sousa Nenê, foi imediata: em carta ao diretor do jornal, replicou todas as acusações, afirmando que as ameaças de expulsão sob o argumento de comunismo eram "nada mais do que 'preparo de terreno' para o que possa acontecer a certos elementos indígenas que estão se tornando inconvenientes, agindo possivelmente por instigação de alguém" . 3 Em resposta à provocação, o jornal informou, numa nova nota, o propósito dos indígenas de irem à sede do SPI, no Rio de Janeiro, para protestar e exigir o título definitivo de seus lotes, e lançou uma advertência: os índios se preparavam " para expulsar de seus postos aqueles que os julguem de raça inferior conforme a concepção dos colonizadores norte-americanos, de que Alaor é um lacaio" . ${ }^{4}$

A advertência não era retórica. As intenções dos índios de ir ao Rio de Janeiro existiram, assim como o plano de atacar o posto, confirmado por várias testemunhas indígenas no inquérito realizado nas semanas seguintes. ${ }^{5} \mathrm{Na}$ verdade, o jornal não fez mais do que divulgar a relação, estabelecida havia tempo, entre comunistas e um grupo de indígenas liderados pelo 
ex-capitão João Mario Fernandes, ${ }^{6}$ e evidenciou um ataque que se havia tornado latente. Nas semanas anteriores, Alaor já escrevera: "deve ser tomada uma providência para pôr um paradeiro nesses comunistas que infestam Dourados e que instigam os índios a se rebelarem, não só contra seus irmãos da selva como contra o pessoal do Posto (...)". 0 encarregado julgava necessário "afastar as cabeças", pois temia que "com o vírus do comunismo no sangue" os índios atacassem "de um momento a outro". " Nesse clima, a IR5 solicitou ao delegado de polícia a investigação dos comunistas, "que têm concorrido para (...) se rebelarem contra a administração daquele posto, havendo aprestamentos de ataque" . ${ }^{8}$

As ameaças dos indígenas não se materializaram. A descoberta da conspiração ou quiçá o temor de serem trasladados para longe, como prometeram fazer os funcionários do SPI, os fizeram desistir. Apesar da derrota, a mobilização continuou. Nos meses seguintes, os indígenas João e Cassiano Aquino, descritos como os "chefes comunistas" mais atuantes, começaram a visitar o PI José Bonifácio. Suas atividades rapidamente incomodaram o encarregado, Pantaleão Barbosa de Oliveira, que solicitou informações sobre sua conduta, já que "vivem cruzando por aqui, apesar de haver ordenado que regressassem ao Francisco Horta, onde pertencem".${ }^{9}$ Conseguiram "seduzir" ao capitão Bibiano Vilhalva, que lideraria a tomada do posto em outubro. Um mês antes da tentativa, $O$ Democrata noticiou a existência de um abaixo assinado escrito pelos índios, acusando Pantaleão de roubar e ameaçar os indígenas com a venda das suas terras. ${ }^{10}$ No seu desabafo ante o chefe da IR5, o encarregado disse que estava inclinado a remover Bibiano do cargo de capitão, colocando em seu lugar Zacarias Marques, um índio da sua confiança. ${ }^{11} 0$ chefe da inspetoria aprovou essa decisão. AconseIhou prudência, e no tom religioso que moldava seu indigenismo, a "elevar o pensamento a Deus, pedindo força para suportar e afastar os maus fluidos que tentam nos envolver". ${ }^{12}$ As pregarias não funcionariam, ao menos no curto prazo.

Na manhã do dia 4 de novembro homens armados tomaram a casa sede do posto. Imobilizaram o encarregado, desarmaram-no, obrigando-o a abandonar o lugar com sua família. 0 plano era fazer com que, em uma humilhante inversão da ordem da autoridade, 0 capitão indígena imposto, Zacarias Marques, saísse junto com eles, montado nas costas do encarregado. Mas Pantaleão aceitou deixar o Posto, evitando uma situação potencialmente trágica. Pediu somente para voltar a fim de realizar a mudança. Os índios aceitaram. 0 capitão Zacarias, por enquanto, ficaria preso. Esta investida contra o SPI também não teve sucesso. 0 encarregado voltou, como disse que faria, porém acompanhado de soldados que controlaram a situação de forma imediata. ${ }^{13}$

Francisco Ibiapina, funcionário do SPI enviado para averiguar os eventos, fez uma avaliação do acontecido, considerando o problema essencialmente como uma iniciativa 
contra a má administração dos Pl. ${ }^{14}$ No entanto, parece que o alcance das ações era muito maior do que o sugerido pelo funcionário. As múltiplas referências a vínculos com o PCB colocam o movimento num contexto de convicções e ideias mais amplas, de articulações além do local, expressas em ações estruturadas, e não simplesmente como um ato de "indisciplina" ou descontentamento. De fato, durante mais de dois anos, anteriormente às tentativas de revolta, e em meio à crise que no âmbito nacional levaria ao fim o governo de Getúlio Vargas e ao longo do processo eleitoral do ano seguinte, os indígenas promoveram reuniões com os seus "instigantes vermelhos"; familiarizaram-se com o jargão partidário, utilizaram a imprensa para seus propósitos, engajaram-se nos movimentos de caráter agrário e, finalmente, celebraram suas próprias eleições para dirimir os conflitos resultantes da divisão entre índios comunistas e não comunistas. As revoltas frustradas em realidade foram o resultado do efeito adverso obtido pelos Kaiowá simpatizantes dos comunistas nessas eleições, celebradas no ano anterior.

\section{Articulaçõés}

$\mathrm{O}$ engajamento na mobilização dirigida pelo PCB não foi incidental. 0 partido tinha uma forte presença nas cidades da região, como Campo Grande e Dourados, fato que favoreceu o engajamento dos indígenas no movimento, pois estes mantinham um convívio próximo com as cidades e as atividades urbanas. Nesse quadro, o vínculo dos Kaiowá com mundo mais amplo da política nacional e dos movimentos sociais foi resultado principalmente do contato com jornalistas da imprensa vinculada PCB. Aqui e acolá, na documentação, vários jornalistas são assinalados como veículos da manipulação comunista: Honório Arce e os irmãos Antônio e João Sobreira, que escreviam para O Democrata, a Imprensa Popular e Voz Operária. Nas páginas desses jornais, eles discutiam os princípios ideológicos do PCB e se pronunciavam a favor da reforma agrária, das lutas populares, denunciando os abusos cometidos contra as classes trabalhadoras e, de vez em vez, as injúrias contra indígenas. ${ }^{15}$

É possível entender a aproximação dos comunistas com os indígenas, e vice-versa, dentro do marco das reformas que o PCB experimentava na época, visando à ampliação da participação de setores anteriormente não considerados. Em meados do século XX, mesmo na ilegalidade, o partido havia alcançado uma considerável força como partido de massas e uma importante presença pública, desenvolvendo uma agressiva atuação de pressão política sobre o governo. Desde 1947, com a ilicitude imposta e sob um clima de repressão, o PCB experimentara uma progressiva radicalização das suas posições, expressas no Manifesto de Janeiro de 1948, e de forma mais acabada no Manifesto de Agosto de 1950. Neste, traçou-se 
uma solução revolucionária, com a classe operária à frente, para derrotar a política de Gaspar Dutra (1946-1951), substituindo-o por um governo democrático-popular. Entre outras coisas, como o estabelecimento de uma Frente Democrática de Libertação Nacional, foi proposto o confisco das grandes propriedades latifundiárias e sua entrega aos camponeses sem ou com pouca terra, e aos trabalhadores agrícolas que quisessem se dedicar à agricultura. 0 dogmatismo continuou prevalecendo, nutrindo uma oposição radical ao presidente Vargas durante quase todo o seu governo (1951-1954), chamado mordazmente, tal como o anterior de Dutra, de traição nacional. Porém a posição "ultraesquerdista" alcançada no Manifesto de Agosto foi se deslocando gradativamente para um "programa de reformas moderadas e com objetivos a curto prazo" (Chilcote, 1982: 107), inclinação manifestada já no IV Congresso, em novembro de 1954, e fortalecida pela trágica conjuntura derivada da morte do presidente. Esta virada reformista levaria à polarização no $\mathrm{V}$ Congresso e, eventualmente, à fratura do Partido em 1962 (Chilcote, 1982; Filho, 2002).

Por enquanto, em 1954, no contexto da discussão do seu programa, os comunistas começavam a projetar a necessidade de uma organização mais ampla e eficaz, impulsionando a participação de mulheres e jovens, e questionando suas estratégias, como a linguagem usada - "manifestação sectária pouco accessível às massas" -, assim como os instrumentos de propaganda, reduzidos a meios escritos. Essas debilidades, apontadas por Mauricio Grabois durante o IV Congresso (PCB, 1954), mas discutidas ao longo de todo o ano nos jornais da imprensa popular, explicam a aproximação do PCB com os indígenas. O Programa incluiria, no ponto 24 da sua terceira parte, seu compromisso com os índios: "ajuda e proteção especial às populações aborígines e defesa de suas terras. Os indígenas terão direito à organização livre e autônoma": nem chefes, nem encarregados.

\section{Comunistas nA Aldeia}

J

á desde os primeiros dias de 1954, dois anos antes das tentativas de revolta, o encarregado do PI Francisco Horta, Alaor Fioravanti, advertira sobre os encontros "clandestinos" entre os Kaiowá e os comunistas. Antes da reunião seguinte, Alaor fez comparecer João Mario Fernandes, então capitão da aldeia, explicou-lhe "o erro que estavam cometendo" e advertiu-o de que, em caso de continuarem recebendo tais pessoas, iria à Polícia; o que fez, de toda forma, encaminhando-se à delegacia para denunciar a atividade dos irmãos Sobreira, os comunistas que "estão procurando jogar os índios contra a administração". A advertência funcionou e a reunião se realizou sem a presença dos comunistas. Mas - afirmou Alaor - "desordem já deixaram. Por mais que a gente explique o que é o comunismo, eles já não creem, 
acham que aqueles é [sic] que estão falando certo, e que nós desviamos todas as verbas que vêm para eles". ${ }^{16}$

Não é possível saber em que termos se desenvolveram, nos meses seguintes, as relações entre os comunistas e os indígenas. Porém é certo que as reuniões "clandestinas" continuaram ao longo de todo esse complicado ano de 1954 e durante 0 ano seguinte. Em 1955, em meio à agitação ocasionada pelo suicídio de Vargas no ano anterior e em vésperas da eleição presidencial a celebrar-se em outubro, a vida política nas aldeias já se orientava de forma determinante segundo os alinhamentos da política nacional. É o que alguns poucos documentos, referências oblíquas da atividade política dos Kaiowá, nos permitem afirmar. Um breve texto escrito pela expedicionária austríaca Wanda Hanke nos oferece um esboço desse período. ${ }^{17}$ Hanke comparou dois momentos distintos no tempo. Em 1949, quando conheceu os Kaiowá do Francisco Horta, levavam "uma vida pacífica, trabalhavam e eram amigos entre eles". Em contraste, quando voltou em 1955, encontrou uma situação lamentavelmente distinta. Os índios "trabalhavam menos, perdendo tempo em disputar o novo e o velho em uma maneira muito infantil e confusa". Diz Hanke: "começam a odiar-se entre eles, desconfiam do chefe do Posto e da Missão [Kaiowá] e mesmo dentro da família se fala demais da política mal compreendida". Inclusive as mulheres, apontou, "menos maduras ainda", perdiam seu tempo falando inutilmente de política. ${ }^{18}$

Hanke identificou os motivos da situação. Alguns irresponsáveis se haviam encarregado de provocar "agitação política", convidando os indígenas a se unirem ao "partido dos trabalhadores, que defende o direito dos pobres, deixando jornais como a Terra Livre e O Novo Mundo, e (...) formulários sobre a reforma agrária para subscrever". Para Hanke, isso era um crime. Ninguém entre os índios, "que ainda são primitivos e têm mentalidade infantil e ingênua" (...) "sabe o que é a reforma agrária; eles não compreendem todo isso que se lhes diz respeito dos direitos do partido". Assim, "se fez uma grande confusão na cabeça deles com o resultado que se dividiram em dois partidos: os novos e os velhos". Ao contrário dos velhos, "os novos não respeitam mais a cruz e a religião e todas as tradições dos antepassados". Também "odeiam o 'Tubarão', que para eles é o Dr. [Antônio] Duarte, do Hospital em Dourados. Porque ele é 'Tubarão', não sabem". No entanto, sabiam: "dizem que ele não gosta dos jornais repartidos e da reforma agrária; e os 'companheiros' do partido Ihe chamam Tubarão". Hanke continua não escutando, e apesar de os índios se queixarem de não receberem medicamentos gratuitamente, afirma: "eles não sabem bem o que querem". Os índios lhe perguntaram o que era o comunismo, se era bom ou ruim. Omitindo sua resposta, afirmou: "não compreendem ainda que os jornais repartidos e os 'amigos do partido' são comunistas". 
A confusão e a ingenuidade também estavam do lado de Hanke. Quando ela esteve pela primeira vez no $\mathrm{Pl}$, a região estava longe de ser um paraíso, uma gemeinschaft aprazível. Em decorrência das políticas de colonização da fronteira, a região havia se constituído em um espaço de conflito. Hanke desconhecia, por exemplo, a violência em que havia resultado o confronto entre os Kaiowá de Panambi e a Colônia Agrícola Nacional de Dourados (CAND), que havia sido localizada nos territórios indígenas a partir de 1943, com a finalidade de promover o estabelecimento de pequenos agricultores. Contudo, e apesar de sua visão da sociedade indígena como um todo orgânico, e de suas convicções sobre a bondade, ingenuidade e ignorância inerente aos índios, Hanke nos ajuda a ver como alguns Kaiowá participavam ativamente do movimento político dominado pelas ideias da esquerda comunista. Hanke afirma esta participação implicitamente, negando-a, como se quisesse extirpar aquilo que, segundo sua visão, não seria essencialmente indígena: os índios aceitaram os jornais, gostavam deles, simpatizavam com a reforma agrária e chamavam os comunistas de "companheiros do partido", confirmando o que, com lamento, Alaor expressara anteriormente: "eles já não creem, acham que aqueles é que estão falando certo (...)" . A política "infantil e confusa" dos índios que não sabiam ler e escrever, estava, de fato, sincronizada com processos muito mais amplos. 0 que a viajante observara era a ativa participação indígena nos eventos nacionais, dominados nesse momento pelo processo eleitoral de 1955. As ideias difundidas em seus encontros com os comunistas estavam sendo reinterpretadas para organizar não apenas suas próprias demandas, mas também seus próprios conflitos internos seguindo os moldes da participação política nacional, reproduzindo quase teatralmente, numa outra escala, a confrontação pelo controle do Estado.

\section{Comunismo indígenA}

$\hat{E}$ difícil indagar o que os Kaiowá entendiam por comunismo, que sentido lhe atribuíam. Porém são compreensíveis algumas das razões pelas quais thes parecia tão atraente um discurso baseado em expressões como "união", "luta libertadora" e "abolição das desigualdades". Dois aspectos que confluíam nesse discurso comunista deviam chamar poderosamente sua atenção e podem explicar seu engajamento no movimento liderado pelo PCB. 0 primeiro, mais abstrato e relacionado às propostas de liberdade e autonomia estabelecidas no Programa de 1954, era a reivindicação das lutas das massas populares, seu triunfo e o eventual estabelecimento de uma sociedade mais justa. 0 Programa do PCB baseava-se na conformação de uma "ampla frente democrática, de libertação nacional, baseada numa aliança operário-camponesa a fim de derrubar o atual regime de latifundiários e grandes capitalistas, 
e substituí-lo pelo regime popular (...)". Esse discurso, nos termos mais simples do jornalista Antônio Sobreira, referia-se à substituição do "regime de tubarões - palavra que Hanke escutara dos Kaiowá - pelo regime que nos ofereça terra, paz e pão"; era inclusive usada a palavra sacrifício para se referir ao esforço que todos deviam empreender na luta libertadora, o que atribuía ao discurso um caráter quase religioso. Foi isso o que entendeu o Kaiowá Júlio Candia, afirmando ter assistido a uma reunião com os comunistas porque lhe disseram que o "comunismo era uma religião muito boa, que ficavam todos como irmãos, que não faltava nada, que se um rico comesse um pão, o pobre come outro pão, também". ${ }^{19}$ Os argumentos que ofereceram à liderança Ireno Isnarde, principal rival dos Kaiowá comunistas, para convencê-lo a participar do movimento, embora os tivesse rejeitado, foram similares: "quando os comunistas ganharem os índios terão de tudo (...) tudo o que os pobres necessitarem". Um outro, negando sua participação nos encontros, declarou que não era comunista e só praticava a religião indígena, sugerindo, portanto, que o comunismo era visto em termos religiosos, embora nos resulte desconhecida a forma como os sistemas de significados se articularam.

O segundo elemento, mais concreto, era o conteúdo agrário do discurso comunista, que associou as reinvindicações indígenas expressamente à luta pela terra. Em meados da década de 1950, houve uma escalada das lutas agrárias dirigidas pelo PCB. O Partido denunciava com vigor a espoliação dos pequenos lavradores, o despejo violento de arrendatários e posseiros, os favores oficiais aos latifundiários, enfim, as caducas relações "feudais", reclamando a modificação da estrutura agrária do país. As denúncias eram acompanhadas por greves de colonos de café, de assalariados agrícolas, pela organização de conferências e congressos, como a II Conferência de Lavradores e Trabalhadores Agrícolas, em São Paulo (Medeiros 1998). Essa intensa mobilização deve ter seduzido os Kaiowá. A luta agrária estava muito próxima. Os colonos da CAND - muitos deles camponeses pobres provenientes do Nordeste - e lavradores de outros lugares, como Itaporã, reclamavam os títulos definitivos das terras, assim como medidas de apoio à produção e a desapropriação de latifúndios. ${ }^{20}$ Era muito fácil se identificar com esses grupos e reivindicações, apesar das diferenças de caráter étnico. Muitos Kaiowá eram peões, empregados em tarefas agrícolas nas fazendas vizinhas. Outros eram lavradores de subsistência que comercializavam uma parte da sua produção na cidade de Dourados. 0 próprio João Mario Fernandes tinha interesse no cultivo comercial de café e algodão, e quando Ihe foi perguntado se era verdade que pretendia adquirir títulos definitivos dos lotes de terra que ocupava, respondeu que sim, se fosse possível, ficando assim "independente do SPI". ${ }^{21}$

Não era apenas uma questão pessoal de João Mario. Os indígenas estavam perdendo rapidamente as poucas terras que lhes restavam. Nas primeiras décadas do século XX, no 
contexto de uma estrutura agrária dominada por imensas áreas arrendadas a empresas estrangeiras, os grupos Guarani que habitavam o extremo sul do estado foram reduzidos a oito minúsculas reservas criadas através de uma série de decretos federais e estaduais entre 1915 e 1928 (Brand, 1997). Grande parte dos seus territórios foi integrada dessa maneira às áreas de extração de erva mate arrendadas pelo estado à Companhia Mate Laranjeira, que teve uma importante presença econômica e política no Mato Grosso durante pouco mais de meio século. A intervenção política do estado quebrou essa estrutura baseada numa economia extrativa, possibilitando o início de um novo ciclo de acumulação capitalista e o estabelecimento de novas relações de produção em vista da integração da região à economia nacional (Foweraker, 1982; Lenharo, 1986; Gressler e Swensson, 1988). A política de colonização impulsionada pelo regime conhecido como Estado Novo (1937-1945) reconfigurou a região, rompendo com o precário equilíbrio estabelecido entre latifúndios, reservas e assentamentos de indígenas dispersos. Em decorrência da correria desatada pela ocupação dos "espaços vazios", os distintos grupos indígenas experimentaram fortes pressões para abandonar seus lugares e para se incorporar, como braço trabalhador, nas fazendas que se multiplicavam rapidamente. 0 processo de ocupação da terra atingiu não apenas os territórios dos índios que moravam fora das reservas, sob o argumento de se acharem em terras devolutas, como as próprias reservas às quais muitos indígenas haviam sido confinados. Ao longo da segunda metade da década de 1940 e, sobretudo, na primeira de 1950, todo o sul do estado habitado por indígenas entrou em conflito (Brand, 1997; Vietta, 2007).

0 assunto da terra passou, dessa forma, a formar parte central das reivindicações dos Kaiowá comunistas. Assim, foi colocado por eles em Dourados, durante o encontro preparatório da celebração da Convenção de Emancipação Nacional no Rio de Janeiro em abril de 1954, que tinha como objetivo a defesa da nacionalização das fontes de energia e a promoção de uma reforma agrária, entre outras coisas. Sabemos da participação dos indígenas no encontro por uma nota publicada na Imprensa Popular.22 Além de denúncias sobre o abandono por parte do SPI, o enriquecimento do encarregado, carências educativas e de saúde, a nota descrevia como a região era alvo constante da ambição de "senhores de terra locais" e "grileiros", que tentavam expulsar os índios para as margens alagadiças do rio Brilhante.

Havia outro conjunto de ofensas que também favoreceriam a adoção do discurso dos comunistas. As condições físicas da população indígena, por exemplo, eram muito precárias. Embora falte uma análise mais profunda, um relatório de 1947 já apontara que o estado sanitário dos Kaiowá era alarmante: mal nutridos e com elevados índices de anemia. ${ }^{23} \mathrm{O}$ SPI, aliás, controlava grande parte dos recursos das reservas e decidia unilateralmente sobre o uso de madeiras, cascas de angico, lenha, pedra, o que era visto compreensivelmente como um 
abuso. Todas as denúncias indígenas vertidas na documentação - sobre terras, saúde, recursos - tinham a ver com problemas reais, concretos dos Kaiowá.

\section{A República NA ALdeia: AS EleiçÕes de 1955}

pós o suicídio do Presidente Vargas, em agosto de 1954, novas condições possibili-
taram a ligação do PCB com as massas getulistas. 0 Partido, sem registro, mas com influência considerável nos setores populares, apoiaria com entusiasmo a chapa Juscelino Kubitschek, do Partido Social Democrático (PSD), e Jango Goulart, do Partido Trabalhista Brasileiro (PTB), para a presidência e vice-presidência da República. No dia 3 de outubro de 1955, Kubitschek e Goulart venceram os candidatos da coligação entre a UDN e outros partidos menores, e em 31 de janeiro de 1956 tomaram posse, após uma frustrada tentativa de impedir que o fizessem.

A intensa campanha eleitoral, marcada por acirradas disputas entre os herdeiros do trabalhismo e as forças conservadoras antigetulistas, prendeu a atenção dos Kaiowá, naquele momento completamente engajados na mobilização liderada pelo PCB. Talvez até mesmo alguns deles estivessem entre a multidão reunida em Dourados para escutar o discurso de João Goulart em agosto de 1955. Não havia outro motivo que não o interesse dos Kaiowá nos processos eleitorais para que o chefe da IR5, Deocleciano de Sousa Nenê, tentasse impedir seu voto, por uma razão aparentemente absurda: eram muito poucos os índios eleitores. Segundo a Constituição Brasileira, e, sobretudo, na opinião do chefe da IR5, os índios deviam permanecer sujeitos à tutela do Estado. ${ }^{24}$ Apenas aqueles que conseguissem atravessar as trevas da selvageria poderiam exercer seus direitos como qualquer outro compatriota civilizado. Mas, de acordo com os critérios utilizados, estes eram muito poucos. Nos 12 PI subordinados à IR5 no sul de Mato Grosso, Deocleciano recolheu sessenta e poucos títulos eleitorais entre uma população de pouco mais de 5.000 indígenas, e se empenhou obstinadamente em solicitar o cancelamento de todos eles, porque "os índios estão sendo instrumentos, porque, sendo eles tutelados, seus votos não poderão ser conscientes". ${ }^{25}$ Porém não conseguiu suprimir 0 interesse dos Kaiowá nos processos eleitorais, inclusive como mecanismo para eleger suas próprias autoridades.

No dia seguinte à eleição presidencial, no PI Francisco Horta, Ireno Isnarde, principal rival político do grupo ligado a membros do PCB, liderado por João Fernandes, chegou até o encarregado perguntando se os comunistas haviam triunfado. Um rumor havia percorrido a aldeia. Dizia-se que, no caso de os comunistas ganharem a eleição, João prenderia Ireno e a todos aqueles que não o apoiassem. 0 encarregado o acalmou: "aí eu estive explicando a 
eles que os comunistas não tinham partido registrado, que não tinham candidato, e fiz ele ver que não tinha perigo algum". 26. Passados uns dias, e num clima de confrontação, João e Ireno acordaram celebrar suas próprias eleições.

No dia 29 de outubro, instalou-se uma mesa no prédio da escola. Tudo composto, Alaor sentou-se no centro da mesa. À sua direita, Ireno, e à sua esquerda, João. Explicado o procedimento aos eleitores, estes deviam se dirigir ao quarto contíguo, onde estariam as cédulas verdes e amarelas com os nomes dos candidatos; depois, colocar a célula escolhida dentro de um envelope e entregar aos mesários. No final do processo, verificou-se a apuração. João Mario Fernandes obteve 40 votos; Ireno Isnarde, 81.

Nas semanas que se seguiram às eleições, 0 Democrata denunciou a interferência do encarregado no processo de eleição. 0 chefe da Inspetoria subestimou 0 artigo: a eleição entre os índios para escolher seus chefes, explicou, "era um caso de competência exclusiva dos agentes encarregados dos postos". ${ }^{27}$ As atividades subversivas dos índios continuaram, em grande parte motivadas pela derrota eleitoral, até que em fevereiro de 1956 a conspiração foi descoberta e a revolta desativada.

\section{A LÓGICA dA CONFRONTAÇÃo INDÍGENA NOS ESPAÇOS CONTROLADOS PELO SPI}

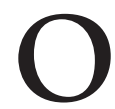

movimento político dos Kaiowá comunistas não tinha a ver apenas com noções de justiça e libertação. As contendas entre os encarregados, capitães indígenas e seus rivais políticos refletiam, de fato, uma lógica muito comum em quase todas as reservas onde o SPI tinha presença através dos PI. Essas relações, descritas na literatura como "entre facções", ou vistas em sua relação com o Estado como clientelísticas (cf. Silva, 2016; Ferreira, 2016; Oliveira, 1988), aqui são entendidas a partir da noção de campo de poder (Roseberry, 1994; Wolf, 2003). Os conflitos são pensados como resultado da ocupação de posições em um triângulo de relações (desiguais) de poder entre a figura do capitão indígena, seus rivais e o encarregado, este último detendo relativa relevância na dinâmica dos conflitos internos.

Em cada Pl, o encarregado reconhecia, e mesmo elegia, como capitão - como "chefe dos índios" - um dos vários líderes que pudessem existir nas distintas aldeias. Nesse sentido, os capitães formavam parte da estrutura do SPI (cf. Oliveira Filho, 1988). Devido a sua posição de poder dentro da reserva e a sua proximidade com o encarregado do posto, o capitão podia ter vários privilégios: ter trabalho pago para ele e seus parentes e receber presentes do encarregado ou de outros agentes, como os missionários. 0 cargo também lhes dava acesso aos funcionários de importância do SPI de forma mais ou menos direta, e cartas eram utilizadas 
para quase todos os propósitos, desde solicitar bens materiais de primeira necessidade a manifestar alguma queixa contra algum funcionário ou denunciar uma invasão de terras.

Era, então, um cargo desejado e, potencialmente, um fator de enfrentamento político entre os distintos grupos. Esses enfrentamentos em parte tinham uma base local, já que as lideranças com frequência representavam não apenas a sua própria parentela, mas também as outras que residiam na mesma aldeia. Essa tendência havia sido o resultado da formação das reservas indígenas nas primeiras décadas do século XX. À sua criação, seguira-se uma política de aldeamento: confinados em espaços reduzidos, o Estado teria mais controle sobre os índios. Sob a ótica dos indigenistas, as reservas também funcionavam como áreas de proteção, em vista dos violentos processos de ocupação do território. Em decorrência do anterior, as aldeias estavam integradas por distintas parentelas, provenientes inclusive de diferentes lugares. Podiam incluir também outros grupos étnicos. O PI Francisco Horta, por exemplo, estava habitado não apenas pelos Kaiowá, mas também por uma minoria Terena de aproximadamente 30 famílias que chegara em vários momentos após a criação da reserva em 1917 (Oliveira, 1976: 87). De forma que era necessário haver uma autoridade política que representasse a todos, e não só a famílias extensas particulares. A bibliografia sobre os grupos Guarani do sul do Mato Grosso com frequência destaca a importância das relações de parentesco para a organização social (cf. Pereira, 1999; Schaden, 1974). No entanto, quando algum conflito irrompia na cotidianidade entre os Kaiowá, como no caso presente, as relações de parentesco, embora fossem importantes, resultavam secundárias ou subordinadas aos arranjos de caráter local.

No contexto dessas lutas pelo controle da aldeia, e tendo em vista que o capitão resultava ser uma pessoa de confiança do encarregado, logicamente ambos eram considerados aliados, e o antagonismo contra um tornava-se extensivo ao outro e vice-versa. Uma forma comum de expressar a oposição a eles era escrever um abaixo assinado manifestando inconformidade contra o capitão, o encarregado ou ambos (também eram comuns cartas a seu favor). No entanto, o equilíbrio das relações entre encarregados e capitães podia ser muito frágil. Qualquer que fosse o motivo para as discrepâncias, os conflitos entre eles eram correntes em quase todos os PI. Uma arma habitual dos capitães contra os encarregados era a mesma que podia se usada contra eles quando aliados: escrever um abaixo assinado expressando uma série de denúncias contra o funcionário. Outra era a confrontação direta ou velada, como ações encaminhadas para incomodar e provocar o encarregado. A resposta deste, de sua parte, era retirar-lhe os benefícios ou substituí-lo, procurando o candidato entre seus rivais ou outros índios de confiança, mas gerando com isso situações potencialmente ainda mais conflitivas.

Todos os elementos descritos estavam presentes no confronto entre o capitão João, liderança dos Kaiowá comunistas, e Ireno Isnarde, seu rival. Os confrontos tinham, em parte, 
essa base local. Eram lideranças de aldeias diferentes dentro da reserva Francisco Horta. João era da aldeia Farinha Seca, localizada nas proximidades da sede do Posto. Ireno era da aldeia Bororó, situada às margens do córrego São Domingos (Girotto, 2007: 75). Embora, para os dois casos, o parentesco fosse importante nas alianças e na conformação dos grupos políticos, foi menor sua importância para João. Ele, à diferença de Ireno, estabeleceu articulações não apenas com membros do PCB, mas também se aliou com alguns Terena habitantes da reserva.

O enfrentamento entre essas lideranças e os grupos que representavam não era de jeito nenhum recente, resultado apenas da sua articulação com os processos de caráter nacional. João Mario Fernandes havia sido reconhecido como capitão oficialmente (pois na prática já exercia a função) pela IR5 apenas alguns anos antes, em abril 1953, quando sucedeu no posto a seu pai, Joaquim Fernandes, que exercera o cargo pelo menos durante 20 anos. Ao longo da sua trajetória, o velho capitão Joaquim havia acumulado prestígio e alguns benefícios materiais. E durante sua chefia, já tivera que afrontar Ireno Isnarde. Em 1945, Ireno e outros indígenas enviaram um abaixo assinado ao General Comandante da 9a Região Militar acusando ao capitão Joaquim de não fornecer assistência nenhuma, de infringir castigos corporais e comerciar bebidas alcoólicas dentro da reserva. ${ }^{28} 0$ documento não estava dirigido unicamente contra Joaquim. 0 capitão, argumentava-se, agira em parceria com o então encarregado do posto. É significativa a similitude entre as reclamações contidas na missiva - falta de atenção médica, ameaças do encarregado - e as realizadas anos depois por João Mario Fernandes e seu grupo contra Alaor Fioravante e publicadas em 0 Democrata, bem como a necessidade, em ambos casos, dos indígenas de procurar algum vínculo externo que pudesse canalizar essas demandas. No caso de Ireno, o abaixo assinado enviado à autoridade militar autorizava um comerciante espanhol a representá-los e "propugnar pelos direitos que se julguem ter" ${ }^{29 .}$ A denúncia tinha sido feita num momento em que o capitão, "velho, cansado e querendo

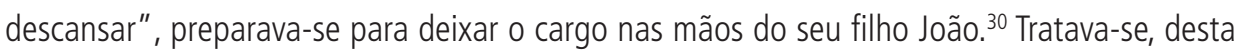
forma, de uma luta pela ocupação do cargo de capitão e pelos benefícios decorrentes, confrontação que continuaria ainda com a chegada de João ao cargo de capitão.

Os conflitos internos no PI José Bonifácio eram, basicamente, da mesma natureza, e é extraordinário o paralelismo do que acontecera com os casos anteriores. As intrigas e disputas entre encarregado, capitão e grupo rival haviam criado uma situação muito semelhante. Bibiano Vilhalva havia sido escolhido como capitão pelo próprio Pantaleão no começo da sua gestão como encarregado. Tratou-se de uma estratégia prudente. Bibiano tinha influência sobre os índios e possuía antecedentes perigosos para o Pantaleão, pois havia se revoltado contra encarregados anteriores. Já como capitão, Bibiano aparece como trabalhador do posto, como empreiteiro no serviço de erva mate; aparentemente, também vendia aguardente 
na aldeia. ${ }^{31}$ Inclusive, Pantaleão e Bibiano tornaram-se compadres. ${ }^{32}$ Entretanto, em algum momento houve um desentendimento entre eles. Em fevereiro de 1954, Pantaleão denunciou que alguns índios liderados pelo capitão se achavam devastando o mandiocal do posto, em consequência do que pretendia fazer uma mudança de capitão. ${ }^{33}$ As coisas seguiram tensas, e em meados do ano o encarregado se encontrava trabalhando sem auxiliar, o que o levou a escrever ao chefe da IR5: "pois como Ihe disse não posso confiar aos índios". ${ }^{34}$ Finalmente, em 1956 aparece a nota, já citada, em O Democrata, responsabilizando a Pantaleão por vários abusos. Como resultado, Pantaleão destituiu Bibiano e, no seu lugar, colocou Zacarias Marques. $^{35}$

Tratando-se de política, nada é linear. A atividade e organização política dos Kaiowá comunistas representava uma tentativa de se livrar dos seus opressores. Mas é claro que também havia interesses pessoais na luta pelo controle do posto e de seus recursos, com sua dinâmica própria, derivada do domínio do SPI através dos postos indígenas. A luta dos Kaiowá junto aos comunistas foi um movimento genuíno de articulação de interesses, e não de manipulação do alto. Mas se houve grande espontaneidade, foi uma espontaneidade orgânica, por assim dizer, canalizada pelas estruturas sociais existentes.

\section{CONCLUSÃO}

$\mathrm{N}$ este texto pretendi mostrar como um movimento político dos Kaiowá contra o domínio exercido pelo SPI articulou-se com outros movimentos de caráter nacional, em particular com a ampla mobilização popular dirigida pelo PCB. Certamente não foi o caso de um grupo que seguiu mecanicamente uma ideologia imposta por uma elite política oportunista. 0 entusiasmo e simpatia manifestados pelo movimento revolucionário não teria tido efeito se não se apoiasse num contexto social e cultural favorável.

De um lado, as propostas de autonomia e de reforma agrária do Programa do PCB de 1954 resultaram adequadas para a realidade indígena na fronteira, caracterizada pelo controle quase total dos seus recursos por parte do SPI e pelo avanço das frentes colonizadoras que transformavam a estrutura agrária em Mato Grosso. De outro, a ideia de transformação do discurso pecebista parece ter encontrado terreno favorável nas ideias religiosas indígenas. É certo que esta afirmação apoia-se apenas em indícios, mas estes são suficientes para afirmar que havia um elemento religioso na interpretação indígena do comunismo. Em ambos os casos, há uma negação ou rejeição da realidade presente e a estimação de uma sociedade futura; busca-se a instauração de uma sociedade livre. Porém apontar de que forma noções centrais à cosmologia Guarani, como a busca da Terra sem Mal ou a noção de Tekoha - território -, 
se articularam com as ideias comunistas representaria um exercício de especulação para além das fronteiras deste artigo. Pareceria arriscado, da mesma forma, sustentar que a adoção Kaiowá daquele discurso, ou de certos elementos, apenas funcionava para encobrir, como uma roupagem externa, um sistema simbólico indígena.

0 que se pode afirmar a partir da documentação disponível é que as ideias comunistas proporcionaram um esquema coerente para estruturar suas próprias demandas e reivindicações em junção com os objetivos de transformação nacional do PCB. Que as revoltas fracassadas dos indígenas representaram uma tentativa de se livrarem dos seus opressores não há duvida: a imagem do encarregado do SPI sendo expulso, montado nas costas do capitão aliado, é mais do que convincente. Entretanto, a reivindicação de um poder indígena, embora frustrada, não deve disfarçar a sociedade indígena de consenso. As ideologias difundidas, inculcadas e, de alguma forma, reelaboradas se articularam também ao contexto dos confrontos locais. É claro que havia interesses pessoais entre grupos na luta pelo controle dos postos. Esses conflitos, como mostrei, eram estruturais e resultavam da ocupação de posições em um triângulo de relações (desiguais) de poder entre a figura do capitão, seus rivais e 0 encarregado, este de relevância na dinâmica dos conflitos internos. Essas relações, no interior dos Pl, eram anteriores e derivavam da estrutura de domínio introduzida pelo órgão indigenista. Enquanto essa estrutura foi predominante, replicada pelo SPI e depois pela FUNAI, esses conflitos típicos pelo controle político das aldeias se reproduziram uma e outra vez, como descrevem alguns trabalhos sobre períodos recentes (cf. Silva, 2016; Ferreira, 2013; Pimentel, 2012). A mobilização política dos Kaiowá junto ao PCB montou-se, ou incrustou-se, sobre esse tipo de relações. Nesse sentido, a divisão entre indígenas comunistas e não comunistas não estabeleceu novas relações. No entanto, esse campo de poder, em que cotidianamente se reproduziam e se redefiniam as desigualdades e a dominação, possibilitou da mesma forma a construção de um movimento político contra esse mesmo poder. Esse foi um traço significativo do seu movimento. A ação política indígena, que por momentos pareceria destinada a permanecer inevitavelmente dentro das estreitas margens da tutela e dos conflitos locais, abriu um breve parêntese nesse cotidiano, outorgando-Ihe outro sentido e outras possibilidades.

\section{NOTAS}

1 Uso a expressão "índios comunistas" para indicar a ativa participação dos Kaiowá junto a membros do PCB, bem como a apropriação indígena de seu discurso, embora a documentação indique que era utilizada principalmente pelo grupo de indígenas contrários e pelos funcionários do SPI.

20 Serviço de Proteção aos Índios e Localização de Trabalhadores Nacionais, SPILTN, depois SPI, foi fundado em 1910 e permaneceu em função até 1967, quando foi substituído pela Fundação Nacional do Índio (Funai). 
3 Museu do Índio (MI) - Fundo SPI (SPI) - 5a Inspetoria Regional (IR5) - 088-07-60-f2.

40 Democrata, 26/02/1956.

5 MI-SPI-IR5-088-087-60-f13-14.

6 A função do capitão, figura instituída pelo SPI, era representar aos indígenas ante a burocracia indigenista; também tinha atribuições de polícia local, devendo fiscalizar os limites das terras e manter a ordem interna. 0 capitão devia escolher seus auxiliares, assim como os integrantes da polícia indígena. Na época, essas autoridades começavam a usar, ou pelo menos solicitar, insígnias e requerer atestados da sua função.

7 MI-SPI-IR-088-087-60-f 8-9.

8 MI-SPI-IR5-088-087-60-f25.

9 MI-SPI-IR5-088-087-60-f27.

10 O Democrata, 09/09/1956.

11 MI-SPI-IR5-092-132-94-f1.

12 MI SPI-IR5-092-132-96-f1-2.

13 MI-SPI-IR5-092-127-39-f 1.

14 MI-SPI-IR5-092-127-39-f 2.

15 Cf. Voz Operaria, 25/07/1953; Imprensa Popular, 14/04/1954 e 01/06/1954.

16 MI-SPI-IR5-088-091-76-f1.

17 Hanke (1933-1958) passou uma parte importante de sua vida viajando e estudando diversos grupos indígenas da Bolívia, Argentina, Paraguai e Brasil. Formada em medicina, direito e filosofia, tinha um amplo interesse na linguística, arqueologia e etnologia dos povos que conheceu (cf. Sombrio, 2011).

18 MI-SPI-IR5-088-087-60-f31-32.

19 MI SPI-IR5-088-087-60-f24.

20 Imprensa Popular, 03/04/1956.

21 MI-SPI-IR5-088-087-60-f16.

22 Imprensa Popular, 08/04/1954.

23 MI-SPI-IR5-088-097-98-f1-5.

24 Sobre o indigenismo e o exercício da tutela cf. Lima (1995) e Oliveira Filho (1988).

25 MI-SPI-IR5-666-294-14-f1.

26 MI-SPI-IR5-088-085-92-f1-2.

27 MI-SPI-IR5-088-085-13-f1-2.

28 MI-SPI-IR5-088-091-05-f1-2.

29 MI-SPI-IR5-088-091-07-f1-2. 
30 MI-SPI-IR5-088-091-06-f1-3.

31 MI-SPI-IR5-999-324-83-f7.

32 MI-SPI-IR5-092-138-42-f1.

33 MI-SPI-IR5-092-138-23-f1.

34 MI-SPI-IR5-092-132-86-f1.

35 MI-SPI-IR5-092-132-94-f1.

\section{REFERÊNCIAS BIBLIOGRÁFICAS}

BRAND, Antônio. O impacto da perda da terra sobre a tradição Kaiowá /Guarani: os difíceis caminhos da Palavra. Tese de História, PUC/RS, 1997.

CHILCOTE, Ronald F. O Partido Comunista Brasileiro: conflito e integração (1922-1972). Rio de Janeiro: Graal, 1982.

CORRIGAN, Philip \& SAYER, Derek. The Great Arch: English State Formation as Cultural Revolution. Oxford: Basil Blakewell, 1985.

FERREIRA, Andrey C. Tutela e resistência indígena: etnografia e historia das relações de poder entre os Terena e o Estado. São Paulo: Edusp, 2013.

FOWERAKER, Joe. A luta pela terra: a economia política da fronteira pioneira no Brasil. Trad. Maria Júlia Goldwassar. Rio de Janeiro: Zahar, 1982.

GIROTTO, Renata Lourenço. O Serviço de Proteção aos Índios e a política indigenista republicana junto aos indios da Reserva de Dourados e Panambizinho na área da educação escolar (1929 a 1968). Tese de História, UNESP, 2007.

GLEDHILL, J. \& SHELL P. A. (orgs.). New Approaches to Resistance in Brazil and México. Durham \& London: Duke University Press, 2012.

GRESSLER, Lori Alice \& SWENSSON, Lauro J. Aspectos históricos do povoamento e da colonização do estado de Mato Grosso do Sul. Dourados: Dag, 1988.

JOSEPH, Gilbert K. \& NUGENT, Daniel (orgs.). Everyday of State Formation. Revolution and Negotiation of Rule in Modern México. Duke University Press, 1994.

LENHARO, Alcir. Colonização e trabalho no Brasil: Amazônia, Nordeste e Centro-Oeste. Campinas: Editora da Unicamp, 1986.

LIMA, Antônio C. (ed.). Um grande cerco de paz: poder tutelar, indianidade e formação de Estado no Brasil. Petrópolis: Vozes, 1995.

Gestar e gerir: estudos para uma antropologia da administração pública. Rio de Janeiro: Nuap I Relume-Dumará, 2002.

LINS, Marcelo da Silva. Os vermelhos nas terras do cacau: a presença comunista no sul da Bahia (1935-1936). Dissertação de Mestrado em História Social, Faculdade de Filosofia e Ciências Humanas da Universidade Federal da Bahia, 2007. 
MEDEIROS, Leonilde. Luta por terra e organização dos trabalhadores rurais: a esquerda no campo nos anos 50/60. In: História do Marxismo, vol. IV. Campinas: Editora da Unicamp, 1998.

NAGLIS, Suzana G. B. Marquei aquele lugar com o suor do meu rosto: os colonos da Colônia Agrícola Nacional de Dourados - CAND, 1943-1960. Dourados: Dissertação de Mestrado em História, UFGD, 2007.

OLIVEIRA, Roberto Cardoso de. Do índio ao bugre: o processo de assimilação dos Terêna. Rio de Janeiro: Francisco Alves, 1976.

OLIVEIRA FILHO, João Pacheco de. O nosso governo: os Ticuna e o regime tutelar. São Paulo: Marco Zero/ Brasília: MCT-CNPq, 1988.

ORTNER, Shery B. Resistance and the Problem of Ethnographic Refusal. Comparative Studies in Society and History, vol. 37, n. 1, 1995.

PARTIDO COMUNISTA DO BRASIL. IV Congresso do Partido Comunista do Brasil, 1954. https://www.marxists. org/portugues/tematica/rev_prob/64/index2.htm.

PEREIRA, Levi M. Parentesco e organização social Kaiowá. Dissertação de Mestrado, Programa de Pós-Graduação em Antropologia Social, Unicamp, 1999.

PIMENTEL, Spensy K. Elementos para uma teoria política Kaoiwá e Guarani. Tese de Doutorado, USP, 2012.

REIS FILHO, Daniel A. Entre reforma e revolução: a trajetória do Partido Comunista no Brasil entre 1943 e 1964. In: RIDENTI, Marcelo \& REIS FILHO, Daniel Aarão (orgs.). História do marxismo no Brasil, vol. V. Campinas: Ed. Unicamp, 2002.

ROSEBERRY, William. Hegemony and the Language of Contention. In: JOSEPH, Gilbert K. \& NUGENT, Daniel (eds.). Everyday of State Formation. Revolution and Negotiation of Rule in Modern México. Duke University Press, 1994.

SCHADEN, Egon. Aspectos fundamentais da cultura Guarani. São Paulo: EPU/EDUSP, 1974.

SILVA, Alexandra Barbosa da. Processos indenitários e relações patrão-cliente entre os Kaiowá. Mana, vol. 22, n. 1, 2016.

SOMBRIO, Mariana M. \& LOPES, M. M. Expedições científicas na América do Sul: a experiência de Wanda Hanke (1933-1958). Cadernos de História da Ciência, vol. 7, 2011.

VIETTA, Katya. História sobre terras e xamãs Kaiowá: territorialidade e organização social na perspectiva dos Kaiowá de Panambizinho (Dourados - MS) após 170 anos de exploração e povoamento não indígena na faixa de fronteira entre o Brasil e Paraguai. Tese de Antropologia Social, USP, 2007.

WOLF, Eric R. Comments on State, Identity and Violence. In: FERGUSON R. B.(ed.). The State, Identity and Violence. Political Desintegration in the Post-Cold War World. New York: Routledge, 2013, p. 61-67. 
